\title{
What Instructional Skills and Strategies Do Competent Mathematics Teachers Use in Teaching Statistics in School Mathematics during PCK Development
}

\author{
S.B. Ijeh ${ }^{1}$ and G.O.M. Onwu ${ }^{2}$ \\ ${ }^{1}$ Department of Mathematics Education, University of South Africa, Muckleneuk Campus, \\ AJH Van Der Walt Building, Room 6-37, South Africa \\ Telephone: 012429 6627, Fax:0865993184,E-mail: ijehsb@unisa.ac.za \\ ${ }^{2}$ University of Pretoria, Greonkloof Campus \\ E-mail: gilbert.onwun@yahoo.com
}

KEYWORDS Pedagogical Content Knowledge (PCK). Statistics. Instructional Skills and Strategies. Competent Mathematics Teachers and Teaching

\begin{abstract}
Pedagogical content knowledge (PCK) comprises subject matter, content knowledge, instructional skills and strategies, conceptions in statistics teaching, and learners' learning difficulties. This study focuses on the instructional skills and strategies used for teaching statistics during PCK development. Research findings show that these skills and strategies are not always apparent. A clear understanding of these skills and strategies, however, would be useful for mathematics teacher education programmes. Of the six mathematics teachers initially chosen because of their school's performance over two years in the senior certificate examination in mathematics, four were selected from the results of a conceptual knowledge exercise (CKE) in statistics for this study, which adopted a qualitative research method. The data on teachers' pedagogical knowledge were collected through a teacher CKE, concept mapping, lesson observation, questionnaire, video recording, teachers' written reports and document analysis. The results indicate that competent mathematics teachers used topic-specific instructional skills and strategies (PCK) in statistics teaching. The implications for mathematics teacher education programmes are also discussed.
\end{abstract}

\section{INTRODUCTION}

Since the 1980s, the International Commission for Mathematics Instruction and the National Council of Teachers of Mathematics (Batanero et al. 2011; NCTM 2012) have investigated issues of particular significance to the theory of classroom practice in mathematics education by organising conferences and workshops on teaching and learning mathematics. This was in response to a worldwide call for an improvement in learners' achievements in school mathematics (TIMSS 2011). Recently, more attention has been paid to statistics, which in most countries is taught as part of the mathematics curriculum. For instance, the 18th Joint Conference of the ICMI and IASE (Batanero et al. 2011) addressed some of the most important aspects of statistics in school mathematics by focusing on education and professional development for teaching.

One of the aspects identified as crucial to improving learners' achievements in statistics is pedagogical content knowledge (PCK) (Shulman 1986). This conference theme was supported by the Umalusi chief examiner's report on learners' performance in data handling (DoBE 2012) at the senior certificate examina- tion, in which learner performance in statistics has not been encouraging since its introduction into school mathematics in South Africa (DoBE 2012). The report indicated that teachers' limited PCK in statistics teaching may have contributed to learners' poor performance, and therefore called on teachers to ensure that learners clearly understood the concepts, by designing good teaching and learning strategies that would enhance their achievements. The question that one needs to ask at this point is: What are the instructional skills and strategies that teachers use for teaching statistics in school statistics?

While most teachers acknowledge the practical importance of statistics and are willing to give more relevance to teaching the topic, many do not consider themselves sufficiently prepared to teach the subject or to face the challenges pose by their learners' learning difficulties because of a poor PCK background in statistics (Watson 2001; Batanero et al. 2011). The chief examiner's report noted that a variety of learning difficulties and misconceptions (DoBE 2012) exist with respect to fundamental statistical ideas with many teachers; hence, the limited PCK they display does not contribute to an improvement in learners' performance. In search of the PCK 
for improving learners' performance in statistics teaching, research on teachers' PCK in statistics appears to be scarce and what is available suggests that knowledge is scanty. This study attempts to investigate the instructional skills and strategies that mathematics teachers demonstrate during statistics classroom teaching and learning. The idea is to present detailed documentation on the way in which practising mathematics teachers develop their PCK in statistics teaching in order to strengthen classroom practice by identifying the instructional skills and strategies.

\section{DESCRIPTION OF PEDAGOGICAL CONTENT KNOWLEDGE}

The concept of pedagogical content knowledge (PCK) was introduced by Shulman (1986) in a paper in which he argued that research on teaching and teacher education ignores matters dealing with the content of lessons, the questions asked and the explanations offered. According to this author, PCK goes beyond knowledge of the subject per se to encompass the dimension of subject matter knowledge for teaching. It refers to the way in which the teacher interprets the subject matter knowledge in the context of facilitating learning.

Shulman (1986), while categorising a knowledge base for teaching, noted that the way in which the subject matter is presented and formulated is a key element in the conceptualisation of PCK. According to him, this knowledge could originate from research or teaching practice. Another element in Shulman's categorisation is knowledge of strategies that may be fruitful in reorganising learners' understanding, and in identifying their preconceptions and misconceptions about a particular topic.

Since Shulman introduced the concept, a number of studies have been carried out on the subject. Various scholars across the discipline have elaborated on his work and have proposed different conceptualisations of PCK (Grossman 1990; Marks 1990; Cochram et al. 1993; Van Driel et al. 1998; Magnusson et al. 1999; Barnett and Hodson 2001; Gess-Newsome and Lederman 2001; Halim and Meerah 2002; Jong 2003). Grossman (1990) developed and expanded the definition of PCK. Her definition is based on four central components: knowledge of learners' understanding, the curriculum, instructional strategies and the purpose of teaching. Knowledge of learners' understanding refers to the ways in which the learners comprehend what is taught to them. In other words, how do learners understand the subject matter being presented to them? While the curriculum pertains to the content of the subject matter, as contained in the curriculum, knowledge of instructional strategies constitutes knowledge of the strategies employed for teaching the subject. The purpose of teaching is the learning outcomes, as outlined in the curriculum. Using these components, Grossman (1990) examined the influence of teacher education on knowledge growth. Grossman's findings demonstrate that teacher education can affect such growth.

Based on an explicit constructivist view of teaching, in their research on PCK as an integrative model for teacher preparation, Cochram et al. (1993) renamed PCK "pedagogical content knowing (PCKg)" in order to acknowledge the dynamic nature of knowledge development. In their model, PCKg is conceptualised far more broadly than in Shulman's view. They define PCKg as "a teacher's integrated understanding of four components of pedagogy, subject matter content knowledge, learner characteristics and the environmental context of teaching" (Cochram et al.1993). According to these authors, $\mathrm{PCKg}$ is generated as a synthesis of the simultaneous development of these four aspects in the context of the integrative model of teaching. Following this argument, it means that the components of PCK, as highlighted above, do not exist independently of one another (Godino et al. 2011). In this study, the identified components of PCK were captured individually during classroom practice, since PCK is individualistic, tacit, and ever changing with time and experience (Miller 2007).

Van Driel et al. (1998) conducted research on developing science teachers' PCK, using classroom observation and interviews. According to them, the idea of integration of knowledge components is central to the way PCK is conceptualised by Jong (2003). These authors identify five knowledge components of PCK: subject matter, the learners, instructional strategies, the teaching context, and the teaching purpose.

Although different researchers have varying opinions about the conceptualisation of PCK, Jong (2003) and Van Driel et al. (1998) state 
that these two elements seem to be germane to any conceptualisation of PCK:

- Knowledge of learners' learning difficulties, conceptions, and misconceptions concerning the topic

- Knowledge of how to represent specific topic

Several scholars have conducted research on PCK development. Their studies are concerned with how a teacher uses his/her knowledge of the content that the learners are expected to learn and of the best approaches to accessing that content; hence, it is called the knowledge base for teaching. A teacher's PCK is therefore unique (Bucat 2004), as it depends on how the teacher interprets learners' preconceptions and learning difficulties and what the learners need to be able to understand the content being taught (Ibeawuchi 2010). The development of PCK is mutual and, hence, the development of one component influences the development of another (Henze et al. 2008). Hill et al. (2008) argue that the impact of teachers' PCK on learners' learning has still to be proven since there seems to be a relationship between teachers' PCK and what the teacher does in the classroom. So far, these authors have agreed that the development of a teacher's PCK is rooted in the classroom and this could contribute to effective teaching and learning of statistics. However, the focus of this study is on the pedagogical knowledge for teaching statistics (Fig.1).

\section{Pedagogical Knowledge}

Pedagogical knowledge is believed to be the kind of knowledge that a teacher needs and uses to perform everyday teaching tasks, involving teaching styles and strategies, and classroom management in the teaching and learning processes relating to learners in the classroom (Cochram et al. 1993; Vistro-Yu 2003). Pedagogical knowledge involves knowing and understanding the content to be taught and the specific demands of that content, such as instructional skills and strategies for teaching it (Ball et al. 2008; Kreber 2004; Laughran et al. 2004). Instructional knowledge involves knowing how to sequence the learning outcomes, preparing the lessons, facilitating discussions and group work, constructing tests, and evaluating learners' understanding through the use of examination, among others (Kreber 2004).

In general, different kinds of instructional strategies, representations and activities are used in teaching mathematics. Representations in-

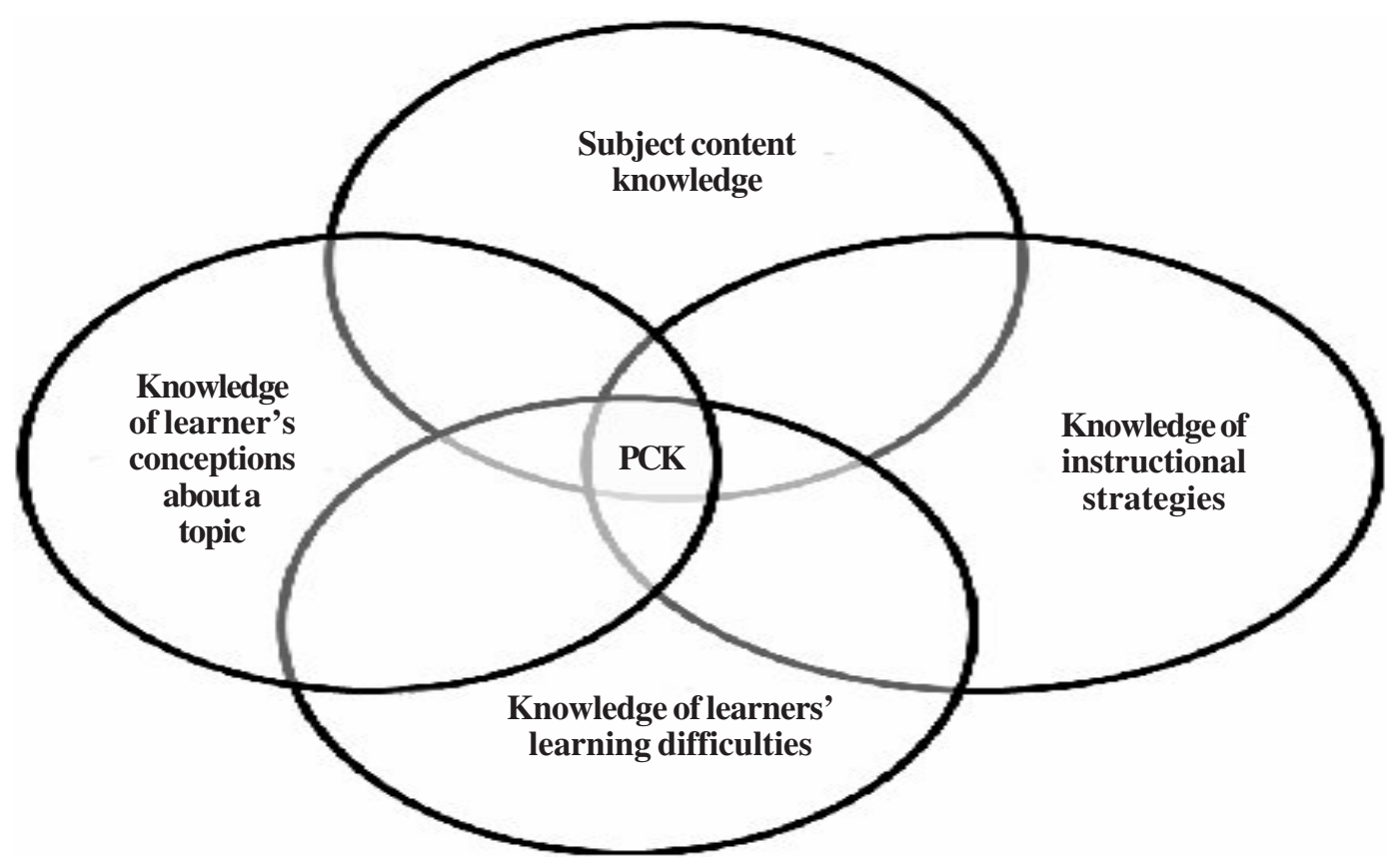

Fig. 1. The components of PCK used in this study (Ijeh 2013) 
clude illustrations, examples, models and analogies. Each representation has a conceptual advantage and disadvantage over other representations (Ibeawuchi 2010). PCK in this area includes knowledge of the relative strengths and weaknesses of a particular representation. Accordingly, activities can be used to help learners understand specific concepts or relationships, for example demonstrations, simulations, investigations and even experimentations. PCK of this type includes teachers' knowledge of the conceptual power of a particular activity (Magnusson et al. 1999). For a representation to be well presented and comprehensible, the teacher must know the learners' conceptions about a particular topic, and also the possible difficulties they will experience during the teaching and learning of the topic. Representations during teaching must be lucidly linked, and the relationships between concepts must be clear (Ibeawuchi 2010). However, many mathematics teachers are not able to identify learner misconceptions or to teach for conceptual change, since they have not yet dealt with their own alternative conceptions, and are working with limited resources, time and necessary skills (Van Driel 1998).

Several studies have highlighted the drawbacks of certain instructional strategies as a component of PCK. Ibeawuchi (2010) for example emphasises that incorrect and misleading representations, such as analogies and examples that depict the teachers' misconceptions, could result from teaching outside one's own field of expertise. Tobin et al. (1994) indicate that when teachers teach outside their areas of specialisation, they give explanations and analogies that reinforce the misconceptions that learners already have.

Magnusson et al. (1999) argue that pedagogical knowledge as a component of PCK is dependent on teachers' subject matter knowledge about a particular concept. This may not always be true, however, as subject matter knowledge does not guarantee that PCK will be transformed into representations that will help learners understand targeted concepts, or that teachers will be able to decide when it is most appropriate pedagogically to use a particular representation. Anderson and Mitchener (1994), in their research on science education, support this view and believe that teachers' knowledge of science teaching may be limited, even if the teachers are familiar with the subject matter. In a particular topic, pedagogical knowledge, or the way concepts are represented as a component of PCK, seems to depend on previous planning, teaching, and reflection (Halim and Meerah 2002).

In conclusion, developing a rich $\mathrm{PCK}$ is a task for highly committed professionals who are willing to address their teaching practice thoughtfully and make substantial changes over time. Practising teachers should strive to integrate everything they know, in order to help learners learn (Griffin et al.1996). Mohr and Townsend (2006) suggest that in-service and pre-service teachers can accomplish these challenging professional tasks by using a comprehensive teaching model. A comprehensive teaching model is a tool for teaching that requires teachers to consider learning theory, learning strategies and assessment. The use of this instrument may influence effective classroom practice and the development of PCK. Hence, the instructional strategies used by the participants in the study for teaching statistics were investigated in the classroom environment. The instructional skills and strategies that teachers with good content knowledge of statistics employ and the way in which they accommodate learners' learning styles were explored. The study therefore seeks to determine the instructional skills and strategies that competent mathematics teachers use in teaching statistics during PCK development. The idea is to provide a detailed description and to document the manner in which the teachers explored the skills and strategies they used for teaching. Teacher trainers could use the process to develop knowledge of instructional skills and strategies to improve the development of educational programmes for in service and pre-service teachers and for continuous improvement of teachers' pedagogical knowledge in statistics teaching.

\section{METHODOLOGY}

This sample consisted of four mathematics teachers teaching Grades 11 and 12. They were identified and selected on the basis of their school's good senior certificate results in mathematics over a period of at least two years and a conceptual knowledge exercise (CKE). Other strategies in selecting the competent teachers were recommendations from principals, peers 
and subject specialists from the Department of Education, as well as interviews with the teachers to determine their educational backgrounds and teaching experience. The research question that guided the study was: What instructional skills and strategies do the identified competent mathematics teachers use in teaching statistics during PCK development?

The study used an essentially qualitative research approach to collect the data. A teacher conceptual knowledge exercise (CKE) and a concept mapping exercise (CME) were used to collect achievement scores, and were used only for selecting the competent mathematics teachers. The primary sources of qualitative data were in-depth teacher structured interviews, artefacts of the interview process, field notes and video recording during lesson observation, completed teacher questionnaires, written documents in the form of teacher written reports and document analyses. All the instruments had their validity and reliability indices determined, as shown in Table 1 . The reliability index of the CKE was calculated as 0.81 .

Table 1: Summary of test characteristics

\begin{tabular}{lcc}
\hline Test characteristics & $\begin{array}{c}\text { Range of values } \\
\text { for test } \\
\text { characteristics }\end{array}$ & $\begin{array}{c}\text { Results from } \\
\text { pilot study }\end{array}$ \\
\hline Reliability & $0.70-1.00$ & 0.81 \\
Discrimination index & $0.3-1.0$ & 0.7 \\
Index of difficulties & $0.4-1.0$ & 0.7 \\
Content validity & 0.97 & 0.7 \\
\hline
\end{tabular}

The validity of the CKE was conducted by giving the exercises to mathematics teachers to ascertain whether the CKE could be used to assess the teachers' knowledge of school statistics and to select participants for the study. The concept map was given to the same mathematics teachers to determine whether the CME would allow them to list the topics according to Grades 10, 11 and 12 and arrange them in logical order, such that one topic formed the basal knowledge of the next for each of those grades. Second, they were required to decide whether the memorandum was appropriate for answering the CME. The interview, questionnaire, and teacher written reports were validated by mathematics education experts using a set of criteria to establish whether these instruments contained appropriate information to determine teachers' mathematics educational background for devel- oping PCK as defined in statistics teaching, what the teacher did while teaching statistics and what made the lesson easy or difficult.

The reliability of the CKE was established through the Kuder-Richardson split half procedure (KR-20, KR-21). The CME and memorandum were given to four school mathematics teachers that did not participate in the study and were physically located outside the study site to avoid contamination. There were consistencies in the responses of the mathematics teachers with the anticipated answers of the CME. The reliability of the teacher interview, questionnaire and written reports was determined by school mathematics teachers who were not involved in the study to determine the extent to which the instruments were likely to yield consistent responses from them (Cresswell 2008) in terms of assessing the mathematics teachers' educational background that may have enabled them to develop their topic-specific PCK in statistics teaching, what the teacher did while teaching statistics and what made the lesson easy or difficult.

The methodology for the study consisted of two phases. In the first phase, the six identified mathematics teachers undertook a written exercise that assessed their conceptual knowledge of statistics. The results of this exercise were used to select the four best-performing teachers for the second phase of the study.

The second phase consisted mainly of concept mapping, lesson observation, interviews, written documents in the form of completed questionnaires, teachers' written reports and document analysis designed to produce rich detailed descriptions of participating teachers' PCK in the context of teaching data-handling concepts at school level. The CME was used to indirectly assess participating teachers' content knowledge and their conceptions of the nature of school statistics and how it is to be taught. The qualitative data obtained were analysed to try to determine individual teachers' content knowledge of school statistics, related pedagogical knowledge, and how they developed their PCK in statistics teaching. The analysis was based on iterative coding and categorisation of responses and observations in order to identify themes, patterns and gaps in school statistics teaching. Commonalities and differences, if any, in the PCK profiles of the four participating teachers were analysed and determined. 


\section{RESULTS}

Teacher A revealed that he has the required content knowledge to teach statistical graphs. He described and demonstrated how to construct a histogram and tried to elucidate the differences between ogives and box-and-whisker plots, using a mostly rule-oriented procedural approach, and less of a conceptual knowledge explanation. Using his procedural knowledge, he followed a stepwise sequential approach to demonstrate the construction of a histogram and box-and-whisker plot: namely drawing the axes, choosing a scale, labelling the axes, plotting the points, and then drawing the line of best fit. Teacher A also applied a conceptual approach in clarifying learners' misunderstanding of how to construct a box-and-whisker plot using the quartiles calculated from the ogive. Other instructional strategies that teacher A applied in his teaching were the use of examples from familiar everyday situations for the histogram. For the ogive and boxand-whisker plot he switched to their mother tongue to reinforce learners' comprehension.

Teacher B demonstrated his knowledge of the content of school statistics, which may have been developed through formal education in teaching ogives and bar graphs with the recommended textbooks and work schedule. Teacher B used appropriate topic-specific instructional skills and strategies, such as examples drawn from familiar situations and a formal procedural approach to teaching the construction of the bar graph and ogive. Learners' misconceptions in drawing a histogram instead a bar graph and the learning difficulties that emanated from these were identified through analysis of their classwork while monitoring, checking and marking learners' responses to their tasks. Further explanations, extra-class activities and postteaching discussion were other strategies that teacher B provided to correct learners' misconceptions and learning difficulties.

Teacher C used appropriate topic-specific scatter plot construction skills of drawing the axes, choosing the scale, labelling the axes, plotting the points and joining the lines of best fit to make data-handling lessons on ogives and scatter plots accessible to more learners. Postactivity and post-teaching discussions were among the instructional strategies he used to address errors and construction difficulties, etc, in ogives and scatter plots. He applied the re- quired diagnostic techniques of oral probing/ questioning, and checking and marking homework at the beginning of the lesson to try to identify learners' prior knowledge of ogive and scatter plot construction. Teacher $\mathrm{C}$ provided additional class activities and individualised teaching, post-teaching discussion on the classwork, and further elucidation on scatter plots immediately after the lesson in order to correct any remaining misconceptions and learning difficulties. On the other hand, teacher $\mathrm{C}$ adapted his conceptual knowledge to explain the construction and interpretation of ogives, especially when learners experienced misconceptions and learning difficulties. For example, when some misinterpreted a negative linear scatter plot as having no correlation because of an outlier, the teacher explained the meaning and nature of the scatter plot and its line of best fit, which can be used to determine the extent of the correlation (strong, moderate, weak or no correlation).

Teacher D demonstrated aspects of procedural knowledge of the topics of bar graph and histogram construction. He combined appropriate pedagogical knowledge of teaching bar graphs and histograms with a rule-oriented procedural and conceptual knowledge approach. The content knowledge of bar graph and histogram construction used for teaching the observed lessons was both procedural and conceptual, but mostly procedural. For example, teacher D demonstrated procedurally how bar graphs and histograms are constructed using the construction skills of drawing the axes, and choosing a scale by considering the lowest and highest values of the data and frequencies, as well as the dimensions of the graph paper provided. At the beginning of the lesson, teacher D used his pedagogical knowledge of instructional skills and strategies to try to identify learners' preconceptions by giving them a pre-activity on the preparation of a frequency table, and by checking and marking their homework on stem-andleaf diagrams. Through the pre-activity, learners demonstrated that they had mastered the concept of preparing a frequency table of ungrouped data and of constructing bar graphs because they had been taught these in the past. Learners' misconceptions and learning difficulties were identified through marking and analysing the learners' classwork, as well as through oral questioning, where learners could request clarification of what they did not understand 
about determining the mode from a histogram. These misconceptions and learning difficulties were not adequately addressed through individual problem-solving class activities and further explanations on the construction and interpretation of bar graphs and histograms, because some learners continued to experience difficulties.

The responses of the four participating teachers to the questionnaire and written reports confirmed that the teachers utilised both procedural and conceptual knowledge approaches, construction skills, extra tutoring, examples drawn from familiar real life situation, and additional class exercises in the form of drill and practice in the teaching of statistical graphs. As observed during the lesson, the documents analysed such as the learners' class workbooks, teachers and learners' portfolios confirmed that the participating teachers also use instructional skills and strategies of additional tutoring, extra class activities, post-teaching discussions, re-teaching, and further explanation of the lessons they taught individually to address learners learning difficulties after the statistics lessons.

\section{DISCUSSION}

The four participating teachers showed similar PCK profiles in terms of subject matter content knowledge, except for qualifications (see Table 2). All four teachers are university graduates in mathematics and statistics. Teachers A and $\mathrm{B}$ have bachelor degrees in mathematics education, and teachers B and C hold BSc qualifications in mathematics and statistics. Teachers $\mathrm{B}$ and $\mathrm{C}$ did not take teaching courses at university, but developed their knowledge of teaching through content knowledge workshops and classroom practice. Their university under- graduate programmes, content knowledge workshops and classroom practice may have provided them with sufficient subject matter knowledge to develop the content knowledge required for teaching statistics, however.

During teaching, all four teachers tried to identify learners' preconceptions in the topics they taught in statistical graphs by using preactivities, oral questioning, and checking and marking learners' homework.

It is clear that the participants are qualified and experienced mathematics teachers and it was assumed that they have sufficient subject matter content knowledge to competently teach statistics in school mathematics. For instance, teachers $\mathrm{A}, \mathrm{B}$ and $\mathrm{C}$ all used oral questioning to identify learners' pre-existing knowledge about the construction of histograms and ogives. Teachers B and D used pre-activities to identify learners' prior knowledge about the construction of bar graphs and teachers A, C and D reviewed previous lessons by checking and marking learners' homework on box-and-whisker plots, scatter plots and histogram construction. In my opinion, the teachers may have adopted the strategies they used to identify learners' preconceptions because of their experience in teaching statistics, as well as knowing which strategy would make it easier for the learners' to understand the topic. But the strategies they employed show that they were deficient in their knowledge of learners' preconceptions, as the strategies could not elicit learners' prior knowledge of the topic.

All four teachers used a predominantly procedural knowledge approach to teaching statistical graphs and thus less frequently a conceptual knowledge approach. Teachers may have adopted more of the procedural knowledge approach because of the learning outcome of data

Table 2: Teacher A, B, C, and D profiles

\begin{tabular}{|c|c|c|c|c|}
\hline $\begin{array}{l}\text { Name of } \\
\text { teacher }\end{array}$ & Qualification & Subject taught & $\begin{array}{l}\text { Teaching } \\
\text { experience } \\
\text { (in years) }\end{array}$ & $\begin{array}{l}\text { Grades } \\
\text { taught }\end{array}$ \\
\hline Teacher A & $\begin{array}{l}\text { BEd (Mathematics Education), BA } \\
\text { (Psychology), Diploma (Mathematics } \\
\text { and Science) }\end{array}$ & Mathematics & 21 years & 11 and 12 \\
\hline Teacher B & BSc (Mathematics and Statistics) & $\begin{array}{l}\text { Mathematics and Mathematical } \\
\text { Literacy }\end{array}$ & 10 years & 11 and 12 \\
\hline Teacher C & BSc (Mathematics) & $\begin{array}{l}\text { Mathematics and Mathematical } \\
\text { Literacy }\end{array}$ & 5 years & 11 and 12 \\
\hline Teacher D & $\begin{array}{l}\text { BEd (Mathematics Education), SED } \\
\text { (Mathematics and Biology) }\end{array}$ & Mathematics & 15 years & 11 and 12 \\
\hline
\end{tabular}


handling as indicated in the National Curriculum Statement (NCS) and the way a particular graph should be constructed, as suggested by Leinhardt et al. (1990).

The learning outcome indicates that learners should be able to collect, organise, construct, analyse and interpret statistical and probability models to solve related problems. Leinhardt et al. (1990) suggest that to understand a graph, one should be able to construct, analyse, interpret and apply knowledge of graphing to solve related problems. The construction of graphs requires scaling, drawing axes, labelling axes, plotting points and joining the lines of best fit. The teachers followed this sequence; hence they used a rule-oriented approach to teaching graphs. For example, teacher A taught his lessons on histogram construction and box-andwhisker plots in a stepwise fashion, moving from the algorithm to the conceptually meaningful stage. He started his lesson by identifying learners' understanding of the concepts of mode, median and mean of ungrouped data by means of oral questioning. The exploration of learners' understanding of these concepts was followed by the teacher and the learners preparing a frequency table together from the raw data to construct a histogram. Using the frequency table, the histogram was constructed by first drawing its horizontal and vertical axes. The axes were labelled as data values on the horizontal axis, and the frequencies on the vertical axis. A scale was chosen by the teacher with the explanation that this was done by considering the highest and lowest values of the respective frequencies and data values. Next, the bars of the histogram were plotted by joining the lines of best fit (Fig. 2).

The use of a conceptual approach may have been designed to cater for problem areas, clarifying misconceptions and learning difficulties, as well as making statistics more comprehensible and accessible to the learners. In this study all participating teachers used the conceptual knowledge approach less frequently, except for teacher B. For instance, teacher A sometimes displayed evidence of a conceptual instructional approach to teaching histograms and stem-andleaf plots. Interestingly, learners seemed to understand the topic better when this approach was used than when the teacher adopted a rule-oriented approach. In the lesson observed, for instance, teacher A explained the mathematical connections and relationships between an ogive and a box-and-whisker plot, using the values of the quartiles from the ogive to construct the boxand-whisker plot (see Fig. 3). In using a conceptual knowledge approach the teacher seems to have exhibited his PCK of teaching box-andwhisker plots and the construction of a histogram in a way that enhanced learners' conceptual understanding of the topic.

As learners became engaged in classwork and problem-solving activities involving calculation, analysis, interpretational and construction skills, while working in groups (as teacher A and D

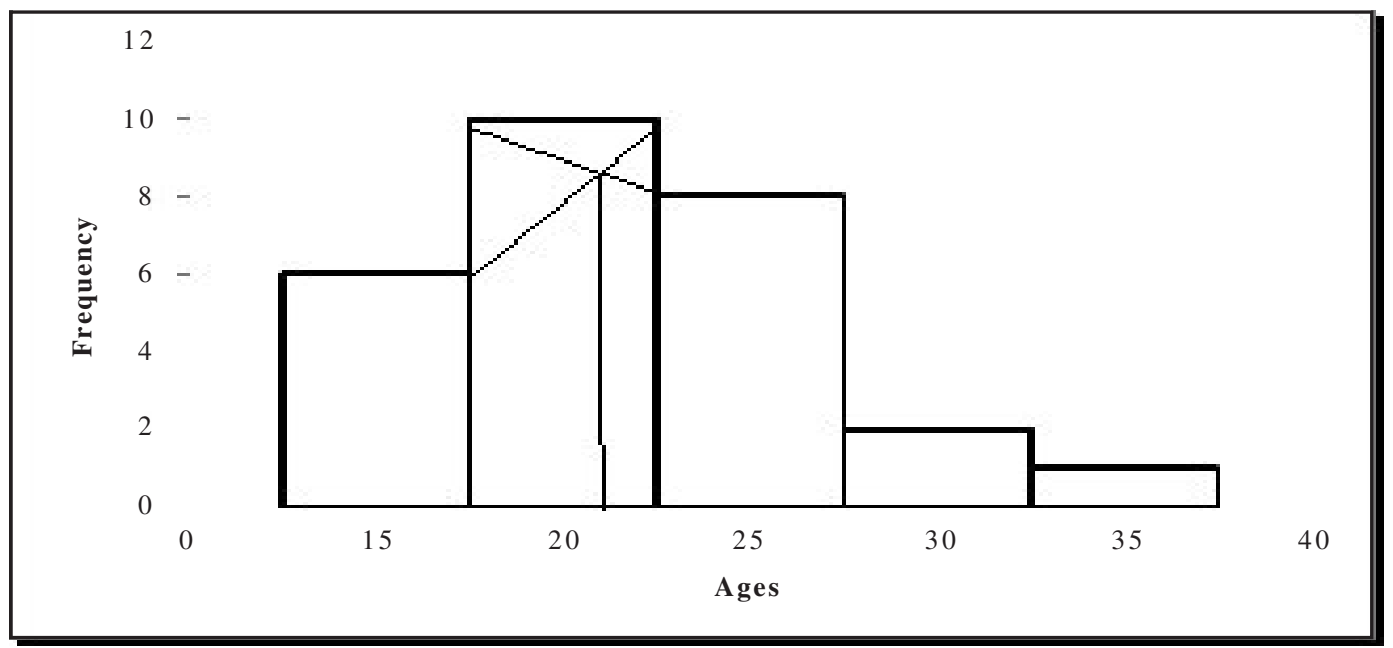

Fig. 2. Age distribution of members of a netball club (Ijeh 2013) 


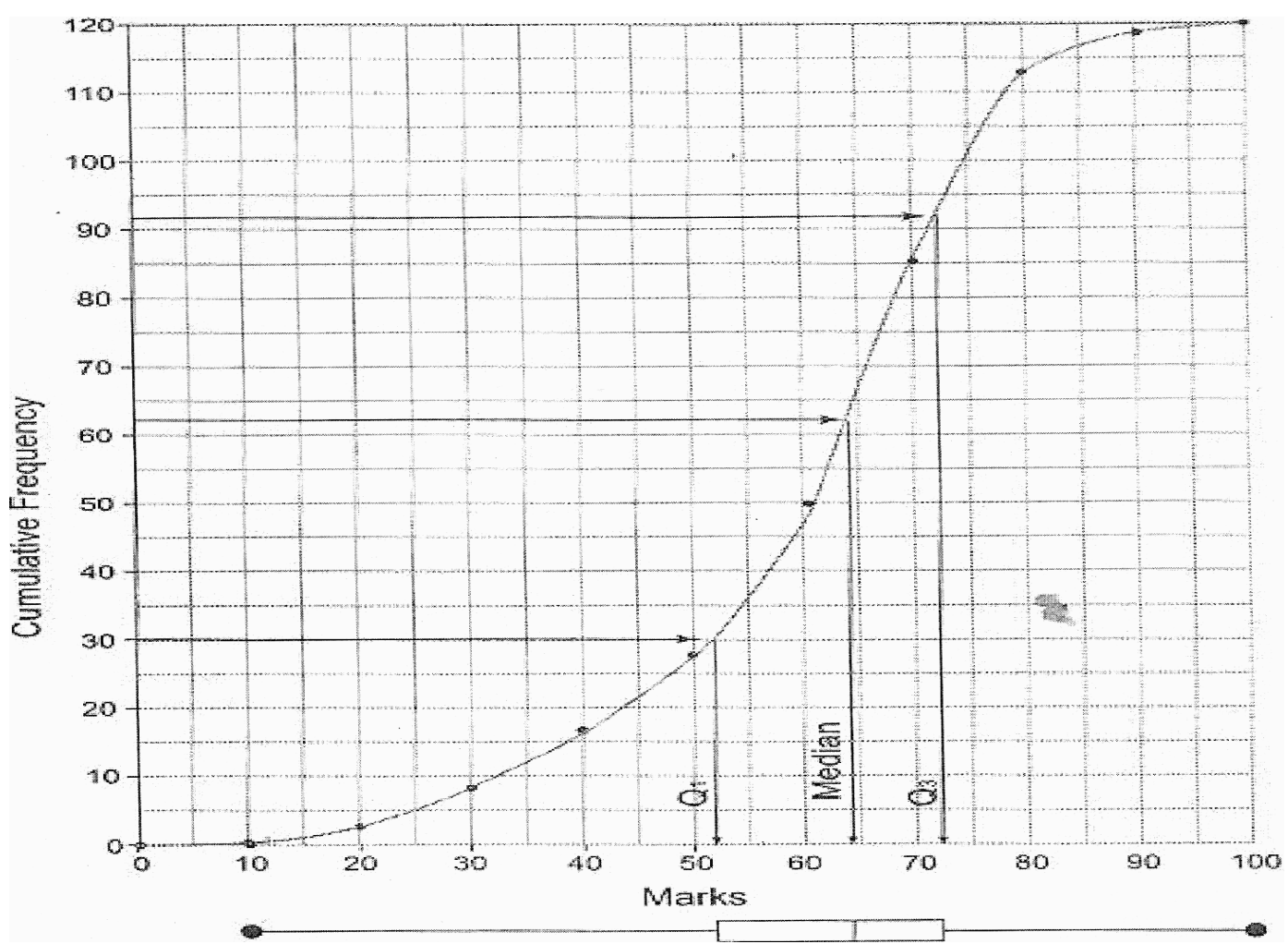

Fig. 3. Ogive and a box-and-whisker plot showing mark distribution of learners in an English examination (Ijeh 2013)

did) or individually, the teachers monitored and guided the learners, sometimes offering advice to learners who were experiencing learning difficulties.

All four teachers analysed learners' classwork, homework, assignment and post-teaching discussion to identify where learners had misconceptions and difficulties. The teachers' written reports and portfolios and the learners' portfolio show similar evidence, as observed in the analysis of classwork, homework and assignments. However, while attempting to address the difficulties learners encountered during teaching, the individual teachers adopted different approaches. For example, teachers A and B used extra tutoring to resolve learners' difficulties. Teacher $\mathrm{C}$ used individualised teaching applicable to real life to try to address learners' misconceptions and difficulties. Like the other participating teachers, teacher B used compulsory exercises, problem-solving activities related to real-life situations, and activities to resolve learning difficulties and misconceptions. All four teachers used post-teaching discussions mainly to address learners' misconceptions.

In terms of the way in which the individual teachers gain knowledge of learners' learning difficulties in statistics by identifying and addressing their difficulties, it appears that the teachers' experience in teaching statistics might have necessitated the choice of the strategies used to identify and address these difficulties. Based on their experience, the teachers may be looking for a more manageable way of delivering statistics content in order to make the lessons more comprehensible and accessible.

Vistro-Yu (2003) and Cochram et al. (1993) acknowledge that most research has shown that teaching experience may allow a teacher to explore various instructional strategies for conducting effective teaching in the classroom context. Jong (2003), Krebber (2004) and Godino et al.(2011) comment that a teacher with adequate PCK should be able to explore various teaching styles and strategies in order to make statistics more readily understood. 


\section{Instructional Skills and Strategies in Teaching Statistics during Pedagogical Content Knowledge Development}

The interviews with the teachers, lessons observation, teachers' written reports, questionnaires and document analyses were used to gather data to determine the pedagogical knowledge that the four teachers used in teaching school statistics.

During lesson observations, some of the teachers used instructional skills and strategies that allowed the learners to actively participate and construct knowledge. These included presenting the learners with problems to solve, with the teacher monitoring and guiding them, especially during classwork. In some instances, learners were grouped together to solve problems. During the case study period, the learners were taught statistical graphs and were assessed through oral questioning, classwork, homework and assignments according to instructional strategies designed by the teachers themselves, in line with the recommendations of the curriculum. These recommendations indicate the learning outcomes of the data handling, stating that the topic should be taught and assessed in line with Bloom's taxonomy and mathematics assessment taxonomies consistent with their PCK profiles. In terms of Bloom's taxonomy, the competencies comprised knowledge, comprehension, application, analysis, synthesis and evaluation as possible indicators that the learner had grasped the meaning of the concept. The mathematics assessment taxonomy also tested knowledge, applying routine procedures to familiar contexts, with multi-step procedures in a variety of contexts, reasoning and reflection (DoBE 2012). Both pedagogical approaches were considered for assessing the learners' competency in statistics.

During classroom practice, teachers used analogies to explain the nature and shape of statistical graphs as a way of improving conceptual understanding. For example, the letter $\mathrm{S}$ was used to describe the nature and shape of an ogive. Teacher $\mathrm{C}$ demonstrated how an ogive is constructed in a step-by-step manner, and the relationship between the constructed $S$ and an ordinary $\mathrm{S}$ which depicted the $\mathrm{S}$ shape of an ogive.

The use of analogy may not have been based on previous planning. Because the teacher was confronted with the learners' learning difficulties, which may not have been predetermined, he decided to exhibit his statistics PCK by using his assumed tacit character to decide which analogy was best to explain the concept of ogives in a way that learners would understand (Halim and Meerah 2002; Park and Oliver 2008). In a way, analogies are used to enable learners to regurgitate and remember. In practice, teachers with good PCK should be able to design instructional strategies that involve effective analogies to explain and make statistics concepts clearer (Jong 2003; Jong et al. 2005; Rollnick et al. 2008).

The instructional strategies adopted, whether procedural or the conceptual knowledge approach may also be dependent on the nature of the topic and the conceptions that learners are expected to have about learning statistics. Both kinds of instructional strategies are important in teaching, depending on which can make the concept more accessible and comprehensible to the learners (Kilpatrick 2002).

The four teachers' understanding of the learners' background knowledge enabled them to teach their lessons in an organised manner. They used specific skills and strategies, probing questioning, pre- and post-activity discussions, familiar examples and mother tongue to make meanings more accessible, on-the-spot checking, and marking the learners' classwork, homework and assignments. Other instructional strategies included analysing learners' assignments and contributions during pre- and post-teaching discussions to determine areas of learning difficulties. Extra tutoring, problem-solving exercises and one-to-one discussions were also used to address learning difficulties.

The findings of Jong (2003), Vistro-Yu (2003), Hill et al. (2008), Rollnick et al.(2008) and Toerien (2011) agree on the use of pre-activities (convergent and inferential techniques), oral questioning, and pre- and post-teaching discussion in teaching statistics. However, the ways that the mathematics teachers gain and use knowledge of instructional skills and strategies are qualitatively different (Gess-Newsome and Lederman 2001) in terms of the relationships of the four components of PCK (Khine 2011). For example, while teacher $B$ tried to determine the learners' pre-existing knowledge about the construction of ogives by oral questioning, teacher $\mathrm{C}$ checked and marked the 
learners' homework on histogram construction. The four teachers predominantly used procedural knowledge and construction skills in teaching data handling. Instructional strategies, such as oral questioning, pre-activities, on-thespot analysis of the learners' classwork, homework, assignments and post-teaching discussions were also used. Other instructional strategies included extra tutoring, individualised teaching on a one-to-one basis, as well as the monitoring and checking the learners' classwork during problem-solving activities. Therefore, knowledge of instructional skills and strategies can be considered a valid construct for describing the PCK of mathematics teachers in teaching statistics.

\section{CONCLUSION}

The choice of instructional skills for teaching statistics may go beyond adopting curricular recommendations for what happens in the classroom. Feedback on learners' classwork, homework and assignments and pre- and postteaching discussions appears to be one of the strongest determinants of instructional skills and strategies for teaching statistics. The findings of this study show that the mathematics teachers used topic-specific instructional skills and strategies. That is, the teachers chose strategies that best suited the topic they were teaching to present the content to the learners in a way that would make learning statistics accessible and comprehensible. Such strategies included the predominant use of a procedural knowledge approach and less frequently a conceptual knowledge approach, problem-solving activities related to familiar situations, extra tutoring as well as monitoring and guiding the learning during classwork in statistical graphs. Teaching and reasoning with data requires different skills from other aspects of mathematics. Practising mathematics teachers who are unfamiliar with the content and with possible learning difficulties may miss opportunities to present far more comprehensible teaching that could assist learners to confront the difficulties and achieve a deeper understanding of the core concepts.

\section{RECOMMENDATIONS}

This study found that procedural and conceptual knowledge were both necessary for teaching statistical graphs, especially in addressing learners' misconceptions and learning difficulties. Further studies are needed to determine how well both approaches can be applied to other aspects of school statistics. More research needs to be conducted into the reasons that teachers with over five years experience of teaching mathematics lack sufficient knowledge of learners' preconceptions in statistics.

\section{REFERENCES}

Anderson RD, Mitchener CP 1994. Research on science teacher education. In: DL Gabriel (Ed.): Handbook of Research on Science Teaching. New York: Macmillan, pp. 3-44. Pythagoras, 55: 58-68.

Ball DL, Thames MH, Phelps G 2008. Content knowledge for teaching: What makes it special? Journal of Teacher Education, 59(5): 589-407.

Barnett J, Hodson D 2001. Pedagogical context knowledge: Toward a fuller understanding of what good science teachers know. Science Education, 85: 426-543.

Batanero C, Burrill G, Reading C 2011. Statistics Education in School Mathematics: Challenges for Teaching and Teacher Education (Executive Summary). Joint ICMI/ IASE Study, DOI 10.1007/978-94-007-1131-0_2, (c) Springer+Business Media B.V 2011.

Bucat R 2004. Implications of chemistry education research for teaching practice: Pedagogical content knowledge as a way forward. Chemistry Education: Research and Practice, 5(3): 215-218.

Cochram TF, De Ruiter JA, King RA 1993. Pedagogical context knowing: An integrative model for teacher preparation. Journal of Teacher Education, 44: 246272.

Creswell JW 2008. Educational Research: Planning, Conducting, and Evaluating Quantitative and Qualitative Research. $3^{\text {rd }}$ Edition. New Jersey: Pearson Educational International.

Department of Basic Education (DoBE) 2012. Report on the National Senior Certificate Examination 2011: National Diagnostic Report on Performance. Pretoria: Government Printer.

Department of Education (DoE) 2007. National Curriculum Statement for Mathematics. Pretoria: Government Printer.

Godino JD, Ortiz JJ, Roa R, Wilhemi MR 2011. Models for statistical pedagogical knowledge. New ICMI Study Series, 14 (3): 271-282.

Gess-Newsome JM, Lederman NG 2001. Examining Pedagogical Content Knowledge: The Construct and its Implications. Science and Technology Education Library, Kluwer Academic Publishers.

Griffin L, Dodds P, Rovengno I 1996. PCK for teachers: Integrate everything you know to help students learn. Journal of Physical Education, 67(9): 58-61.

Grossman R 1990. The Making of a Teacher: Teacher Knowledge and Teacher Education. New York/ London: Teachers College Press.

Halim L, Meerah SM 2002. Science trainee teachers' pedagogical content knowledge and its influence on physics teaching. Research in Science and Technological Education, 20(2): 215-225. 
Henze I, Van Driel JH, Verloop N 2008. Development of experienced science teachers' pedagogical content knowledge of models of the solar system and the universe. International Journal of Science Education, 30(10): 1321-1342

Hill HC, Blunk M, Charalambous C, Lewis J, Phelps G, Sleep L, Ball DL 2008. Mathematical knowledge for teaching and the mathematical quality of instruction: An exploratory study. Cognition and Instruction, 26(4): 430-511.

Ibeawuchi OE 2010. The Role of Pedagogical Content Knowledge in the Learning of Quadratic Functions. MEd Thesis, University of South Africa, South Africa.

Ijeh SB 2013. How competent mathematics teachers develop pedagogical content knowledge in statistics teaching. $\mathrm{PhD}$ Thesis, University of Pretoria.

Jong OD 2003. Exploring science teachers' PCK. In: D Psillos (Eds.): Science Education Research in the KnowledgeBased Society. Dordrecht: Kluwer Academic, pp. 373381.

Jong OD, Van Driel JH, Verloop N 2005. Pre-service teachers' pedagogical content knowledge of using particle models in teaching chemistry. Journal for Research in Science Teaching, 42(8): 947-964.

Kilpatrick J 2002. Helping Children Learn Mathematics. National Research Council: National Academic Press.

Khine MS 2011. Models and Modeling: Cognitive Tools for Scientific Enquiry. Dordrecht: Springer.

Krebber C 2004. An analysis of two models of reflection and their implications for educational development. International Journal for Academic Development, 9(1): 29-49.

Laughran J, Mulhall P, Berry A 2004. In search of pedagogical content knowledge in science: Developing ways of articulating and documenting professional practice. Journal of Research in Science Teaching, 41(4): 370-391.

Leinhardt G, Zaslavsky O, Stein MK 1990. Functions, graphs, and graphing: Tasks, learning and teaching. Review of Educational Research, 60(1): 1-64.

Magnusson S, Krajcik H, Borko H 1999. Nature, sources and development of PCK. In: J Gess-Newsome, NG Lederman (Eds.): Examining PCK. Dordrecht: Kluwer Academic, pp. 95-132.

Marks R 1990. Pedagogical content knowledge: From a mathematical case to a modified conception. Journal of Teacher Education, 41(3): 3-11.
Miller LM 2007. Pedagogical content knowledge. In: G M Bodner, M Orgill (Eds.): Theoretical Frameworks for Researchers in Chemistry/Science Education. USA: Pearson Education, pp. 86-104.

Mohr DJ, Townsend JS 2006. Research to practice: Using comprehensive teaching models to enhance PCK. Teaching Elementary Physical Education, 13(4): 26.

NCTM 2012. Principles and Standards of School Mathematics. Reston, VA, USA: NCTM.

Park S. Oliver JS 2008. Revisiting the conceptual understanding of PCK as a conceptual tool to understand teachers as professionals. Research in Science Education, 38(3): 261-284.

Rollnick M, Bennett J, Rhemtula M, Dharsey N, Ndlovu T 2008. The place of subject matter knowledge in pedagogical content knowledge: A case study of South African Teachers teaching the amount of substance and chemical equilibrium. International Journal of Science Education, 30(10): 1365-1387.

Shulman LS 1986. Those who understand: Knowledge growth in teaching. Educational Researcher, 15: 4-14.

TIMSS 2011. What Happens to the Results of TIMSS 2011? IEA Reports 2011. TIMSS \& PIRLS International Study Center, Lynch School of Education, Boston College, Chestnut Hill, MA and International Association for the Evaluation of Educational Achievement (IEA), IEA Secretariat, Amsterdam, the Netherlands.

Tobin K, Tippins D, Gallard AJ 1994. Research on instructional strategies for teaching science. In: DL Gabel (Ed.): Handbook of Research on Science Teaching and Learning. New York: Macmillan, pp. 45-93.

Toerien R 2011. A Case Study of the Pedagogical Content Knowledge of In-service Science Teachers Teaching Organic Chemistry in Two South African Secondary Schools. Cape Town: University of Cape Town.

Van Driel J, Verloop N, De Vos W 1998. Developing science teachers' pedagogical content knowledge. Journal for Research in Science Teaching, 35(6): 673-695.

Vistro-Yu CP 2003. On Pedagogical Knowledge in Mathematics: How Secondary School Mathematics Teachers Face the Challenge of Teaching a New Class. Quezon City, Philippines: Ateneo de Manila University.

Watson JM 2001. Profiling teachers' competence and confidence to teach particular mathematics topics: The case of chance and data. Journal of Mathematics Teacher Education, 4: 305-337. 